\title{
The Immediate Effect of Ankle Balance Taping using Kinesiology Tape on the Weight-bearing Ankle Dorsiflexion Range of Motion and the Dynamic Balance in Asymptomatic Subjects
}

\author{
Byeong-Jo Kim, PT, PhD, Jung-Hoon Lee, PT, $\mathrm{PhD}^{\dagger}$, Jin-Tae Han, PT, $\mathrm{PhD}^{1}$
}

Department of Physical Therapy, College of Nursing and Healthcare Sciences, Dong-eui University

${ }^{1}$ Department of Physical Therapy, College of Science, Kyung-sung University

Received: July 3, 2014 / Revised: August 13, 2014 / Accepted: August 14, 2014

(c) 2014 J Korean Soc Phys Med

\section{| Abstract |}

PURPOSE: The purpose of this study was to examine the immediate changes in the weight-bearing ankle dorsiflexion range of motion (ROM) and the dynamic balance in asymptomatic subjects using the modified Star Excursion Balance Test (SEBT) after ankle balance taping (ABT) and placebo ABT with kinesiology tape

METHODS: A total of 23 active participants (11 men, 12 women) volunteered for this study. Ankle flexibility was assessed using the weight-bearing lunge test, and dynamic balance was assessed using the modified SEBT. Participants were asked to respond to questions regarding their perception of stability, reassurance, and confidence when performing modified SEBT.

RESULTS: The weight-bearing ankle dorsiflexion ROM did not show a significant decrease after real ABT or placebo ABT compared to the ROM prior to ABT. The anterior, posterolateral, and posteromedial reach distances of SEBT

$\dagger$ Corresponding Author : dreampt@deu.ac.kr

This is an Open Access article distributed under the terms of the Creative Commons Attribution Non-Commercial License (http://creativecommons.org/licenses/by-nc/3.0) which permits unrestricted non-commercial use, distribution, and reproduction in any medium, provided the original work is properly cited. did not increase significantly after real ABT or placebo ABT compared to the distances prior to ABT. However, the participants'perception of stability, reassurance, and confidence, when performing SEBT with real ABT, was increased compared to that during the control trial.

CONCLUSION: This study showed that although real ABT did not immediately improve the reach distances in the 3 directions during modified SEBT, it improved the participants'perception of stability, reassurance, and confidence without decreasing weight-bearing ankle dorsiflexion ROM.

Key Words: Ankle balance taping, Ankle dorsiflexion, Confidence, Dynamic balance, Kinesiology taping

\section{Introduction}

Ankle injuries are common during recreational activities and sports (Bell et al, 2011) and $85 \%$ of these injuries are ankle sprains (Liu and Nguyen, 1999). Recurrence rates of ankle sprains are high (Janssen et al, 2014), and recurrence may cause chronic ankle instability, peroneal tendon pathology, anterior ankle impingement, and osteoarthritis, requiring prolonged therapy (Sugimoto et al, 
2009). Therefore, prevention of ankle sprain recurrence is the primary focus of treatment (Sawkins et al, 2007). Generally, ankle taping using non-elastic tape or bracing is used as a means of preventing further ankle injury (Janssen and Kamper, 2013). Taping provides mechanical support to the ankle (Kemler et al, 2011) by restricting ankle ROM (Bunch et al, 1985) and by improving proprioception (Kemler et al, 2011). However, some studies conducted previously on the functional performance effects of ankle taping using non-elastic tape or various braces have shown that it interferes with normal function (Metcalfe et al, 1997).

Kinesiology taping (KT), using elastic tape, is now increasingly applied to treat a variety of neuromuscular (Yasukawa et al, 2006; Cortesi et al, 2011), sports-related (Merino et al, 2011; Lee and Yoo, 2012c), and orthopedic conditions (Kaya et al, 2011; García-Muro et al, 2010). Previously conducted studies have shown that KT improves blood flow and lymph circulation (Kase et al, 2003), improves proprioception by stimulating cutaneous mechanoreceptors (Murray and Husk, 2001; Chang et al, 2010), assists muscle function (Cortesi et al, 2011; Huang et al, 2011) relieves pain (Kaya et al, 2011; García-Muro et al, 2010; Hwang-Bo and Lee, 2011; Lee and Yoo, 2012c), and aids the mechanical effects required for correction of misalignment of the pelvis (Lee and Yoo, 2012a; Lee et al, 2011) and the shoulder (Lee and Yoo, 2012b).

Postural balance is a necessary component of daily and sport activities (Bell et al, 2011) In addition, limitation of ankle ROM affects daily activities such as running, walking, squatting, and stair climbing (Green et al, 2001). However, the effects of ABT, with kinesiology tape, on the ankle ROM and the dynamic balance of asymptomatic subjects have not been studied sufficiently. Therefore, the purpose of this study was to investigate the changes in the weight-bearing ankle dorsiflexion ROM and the dynamic balance of asymptomatic subjects after application of different types of ABT using kinesiology tape.

\section{Materials and Methods}

\section{Participants}

A total of 23 active participants (11 men, 12 women) volunteered for this study. The participants were selected according to the following criteria: (1) no history of fracture, strain, or sprain of the ankle or lower extremity in the 6 months prior to formal testing, (2) the absence of cerebral concussions, and vestibular disorders (Olmsted et al, 2002), and (3) no limitation of hip, knee, and ankle joint ROM. One male participant was excluded because of a history of ankle fracture, in the 6 months prior to testing. The demographic characteristics of the participants are displayed in Table 1. Informed consent was obtained from all participants prior to study participation.

Table 1. Baseline characteristics of the participants $(n=22)$

\begin{tabular}{ccc}
\hline \multirow{2}{*}{ Variable } & \multicolumn{2}{c}{ mean \pm SD } \\
\cline { 2 - 3 } & Male $(\mathrm{n}=10)$ & Female $(\mathrm{n}=12)$ \\
\hline Age (years) & $24.40 \pm 7.12^{*}$ & $21.92 \pm 0.51$ \\
Height $(\mathrm{cm})$ & $174.50 \pm 4.40$ & $161.83 \pm 3.71$ \\
Weight $(\mathrm{kg})$ & $66.95 \pm 6.83$ & $63.50 \pm 7.59$ \\
\hline
\end{tabular}

\section{Measurements}

1) Measurement of the weight-bearing lunge test

The weight-bearing lunge test can be used to assess ankle dorsiflexion ROM and ankle flexibility (Jones et al, 2005). Bennell et al. (1998) described a testing protocol, which involved the participants placing their foot perpendicular to a wall and lunging their knee as much as possible until the maximum range of ankle dorsiflexion was reached without lifting the heel. At the maximum lunge point, the rater measured the distance from the big toe to the wall using a tapeline (Bennell et al, 1998) (Fig 1). 


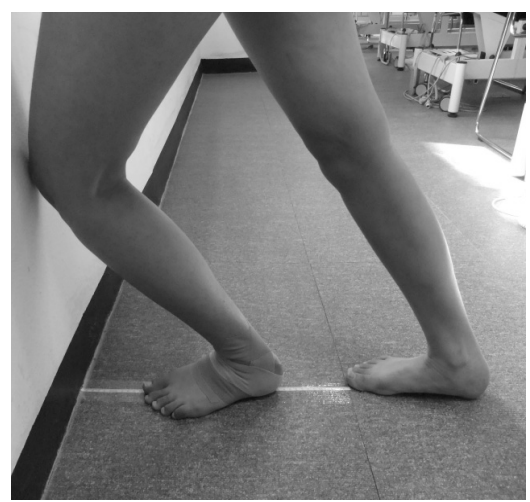

Fig 1. Measurement of the weightbearing ankle dorsiflexion range of motion of the left leg with real ankle balance taping

\section{2) Measurement of modified SEBT}

The SEBT is an inexpensive, fast, and reliable test for measuring dynamic balance (Hertel et al, 2000; Kinzey and Armstrong, 1998). The 3 selected directions (anterior, posteromedial, and posterolateral) of the SEBT (Coughlan et al, 2012) were constructed using a $5 \mathrm{~cm}$-wide adhesive masking tape on hard tile floor.

The participants were asked to maintain a single-leg stand in the center of a grid formed by 3 lines (Gribble and Hertel, 2003), reach as far as possible, touch the line with the reaching leg, and return to a double-leg stance in the center (Gribble et al, 2012) (Fig 2). Each participant practiced 6 trials in each of the 3 directions for each leg before starting the formal experiment (Olmsted et al, 2002) and performed 1 trial in each of the 3 directions to reduce the learning effect. They made the reach in the 3 directions in a clockwise order (Gribble and Hertel, 2003). The trials were discarded and repeated if the participant (1) failed to maintain 1 leg stance, (2) moved or lifted the stance leg from the center grid, (3) did not touch down with the reaching leg while maintaining the 1 leg stance, or (4) failed to return the reaching leg to the center (Plisky et al, 2006).

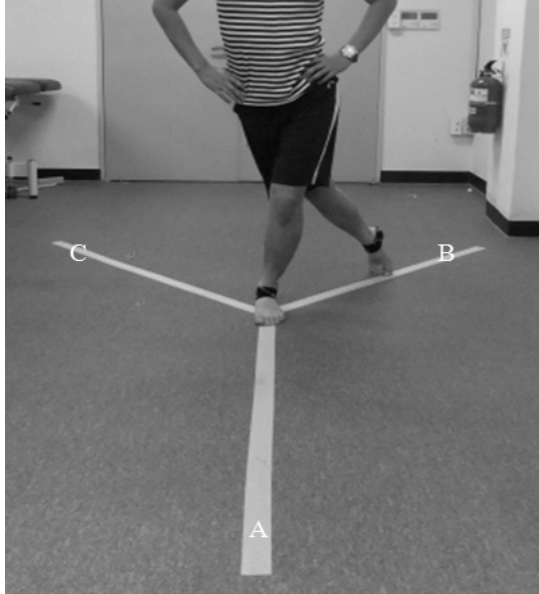

Fig 2. Performance of the Star Excursion Balance Test with the right leg with real ankle balance taping in the $(A)$ anterior, (B) posterolateral, and (C) posteromedial directions

3) Perception of stability, reassurance, and confidence Participants were asked to respond to questions regarding their perception of stability, reassurance, and confidence when performing modified SEBT compared to that during the control trial (Sawkins et al, 2007).

\section{4) Kinesiology tape application}

The kinesiology tape (BB TAPE, WETAPE Co., Ltd, Seoul, Korea) was applied with approximately 30-40\% stretch by a single physical therapist with over 10 years of experience in kinesiology taping methods for each tape condition. Before kinesiology taping, the participants sat in a relaxed position. For the real ABT, the kinesiology taping was carried out in 4 steps. The first strip of tape was wrapped from the talus to the calcaneus (Fig 3A) with the ankle in slight dorsiflexion. The second strip of tape was applied from $5 \mathrm{~cm}$ above the medial malleolus going over the lateral calcaneus to the outside of the instep (Fig 3B), with the ankle in slight inversion. The third strip of tape was applied from $5 \mathrm{~cm}$ above the lateral malleolus going over the medial calcaneus to the inside of the instep (Fig 3C), with the ankle in slight eversion. The fourth strip 
of tape was applied over the area of the first tape, overlaying $100 \%$ of it to enhance the support to the ankle (Fig 3D), with the ankle in slight dorsiflexion.

For the placebo ABT, the taping was carried out in 2 steps. The first strip of tape was applied from below the lateral calcaneus to one-half of the lateral area of the lower extremity (Fig 4A). The second strip of tape was applied from below the medial malleolus to one-half of the medial area of the lower extremity (Fig 4B).

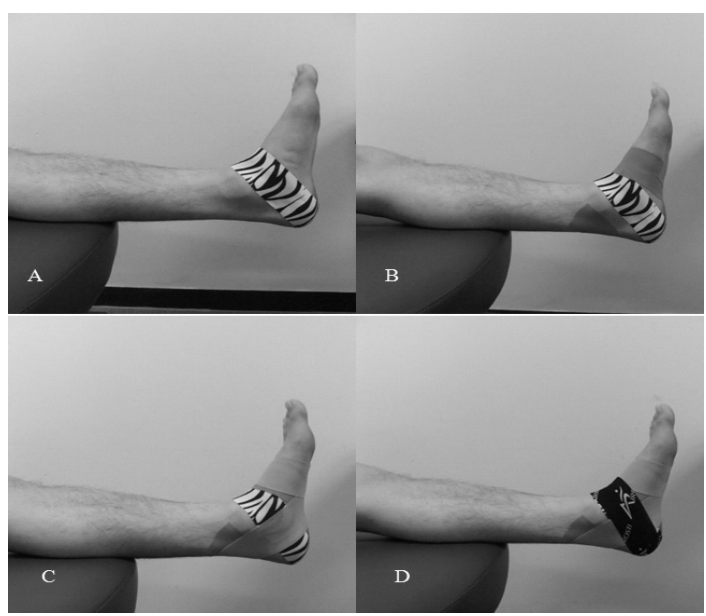

Fig 3. Real ankle balance taping using kinesiology tape; (A) the first tape was wrapped from the talus to the both calcaneus; (B) the second tape was applied from $5 \mathrm{~cm}$ above the medial malleolus going over the lateral calcaneus to the inside of the instep; (C) the third tape was applied from $5 \mathrm{~cm}$ above the lateral malleolus going over the medial calcaneus to the outside of the instep; (D) the fourth tape was laid over $100 \%$ of the first tape for enhancement of ankle support

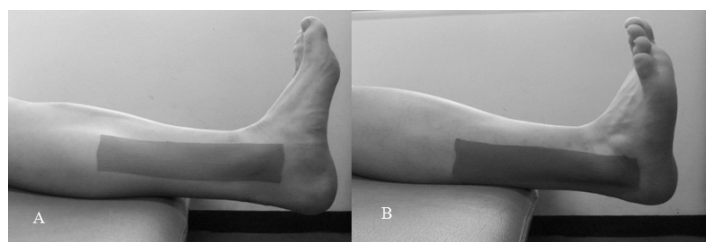

Fig 4. Placebo ankle balance taping using kinesiology tape; (A) kinesiology taping for the medial area of the left limb; (B) kinesiology taping for the lateral area of the right limb

\section{5) Procedure}

The participants'ankles (both) were assessed under 3 conditions (no taping, real ABT using kinesiology tape, and placebo $\mathrm{ABT}$ using kinesiology tape) at 1-week intervals, in random order. An assistant, who was not participating in the experiment, controlled the random order. The weight-bearing ankle dorsiflexion ROM and the dynamic balance (using the modified SEBT) were assessed before and after each of the 3 conditions by a single physical therapist with over 10 years of experience.

\section{Data analysis}

Statistical analyses were performed using the SPSS software (version 18.0; SPSS, Chicago, IL, USA). The one-way analysis of variance was used to analyze immediate changes in the weight-bearing ankle dorsiflexion ROM and the reach distances of the 3 selected directions of SEBT on 1 within-subject factor (three conditions: no taping, real $\mathrm{ABT}$, and placebo $\mathrm{ABT}$ ). A value of $p<0.05$ was considered statistically significant.

An analysis of the participants' perception of stability, reassurance, and confidence during modified SEBT compared to that during the control trial was performed. The chi-square test was used to analyze the difference between the proportions of each perception provided by the participants for each of the ABT conditions.

\section{Results}

1. The weight-bearing ankle dorsiflexion ROM

There were no significant differences found in the weight-bearing ankle dorsiflexion ROM among the 3 conditions $(p>0.05)$ (Table 2).

\section{The reach distances of the anterior,} posterolateral, and posteromedial directions

There were no significant differences in the reach 
The Immediate Effect of Ankle Balance Taping using Kinesiology Tape on the Weight-bearing Ankle Dorsiflexion Range of Motion and the Dynamic Balance in Asymptomatic Subjects | 267

Table 2. Comparison of the weight-bearing ankle dorsiflexion range of motion among the 3 conditions

\begin{tabular}{ccccc}
\hline \multirow{2}{*}{ Angle } & \multicolumn{3}{c}{ mean \pm SD (Degrees) } & $\mathrm{p}$ \\
\cline { 2 - 4 } & No taping & Placebo ABT & Real ABT & 0.40 \\
Dominant & $10.42 \pm 2.05$ & $10.26 \pm 2.50$ & $11.15 \pm 2.41$ & 0.83 \\
Nondominant & $10.71 \pm 2.38$ & $10.40 \pm 2.20$ & $10.81 \pm 2.45$ & 0.85 \\
\hline
\end{tabular}

ABT : ankle balance taping

Table 3. Comparison of the reach distances in the 3 directions among the 3 conditions

\begin{tabular}{|c|c|c|c|c|}
\hline \multirow{2}{*}{ Distance } & \multicolumn{3}{|c|}{ mean $\pm \mathrm{SD}(\mathrm{cm})$} & \multirow{2}{*}{$\mathrm{p}$} \\
\hline & No taping & Placebo ABT & Real ABT & \\
\hline Anteriro (dominant) & $70.77 \pm 4.97$ & $71.63 \pm 4.90$ & $7.82 \pm 4.96$ & 0.81 \\
\hline Anterior (nondominant) & $69.94 \pm 4.07$ & $71.56 \pm 3.85$ & $72.24 \pm 4.41$ & 0.17 \\
\hline Posteromedial (dominant) & $70.86 \pm 10.46$ & $69.25 \pm 9.17$ & $73.60 \pm 8.88$ & 0.32 \\
\hline Posteromedial(nondominant) & $71.45 \pm 10.09$ & $72.25 \pm 8.03$ & $76.47 \pm 8.97$ & 0.15 \\
\hline Posterolateral (dominant) & $68.82 \pm 12.29$ & $72.91 \pm 10.85$ & $73.78 \pm 12.08$ & 0.33 \\
\hline Posterolateral (nondominant) & $67.61 \pm 10.12$ & $71.60 \pm 10.82$ & $73.05 \pm 12.60$ & 0.26 \\
\hline
\end{tabular}

ABT : ankle balance taping

distances of the lower extremities in the anterior, posterolateral, and posteromedial directions among the 3 conditions $(p>0.05)$ (Table 3).

\section{Perception of stability, reassurance, and confidence}

The real ABT and the placebo ABT influenced the participants'perception of stability, reassurance, and confidence, when performing the modified SEBT (Fig 5). The participants who underwent real ABT reported improvement in stability $(73 \%, \mathrm{~N}=16)$, reassurance $(68 \%$, $\mathrm{N}=15)$, and confidence $(68 \%, \mathrm{~N}=15)$ when compared to their perception of these factors during the control trial. The participants who underwent placebo ABT also reported improvement in stability $(23 \%, \mathrm{~N}=5)$, reassurance $(18 \%, \mathrm{~N}=4)$, and confidence $(14 \%, \mathrm{~N}=$ $3)$ when compared to their perception of these factors during the control trial.

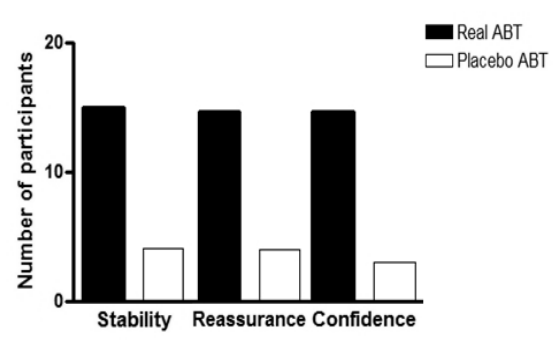

Fig 5. Participants'perceptions of stability, reassurance, and confidence in the 3 selected directions of the Star Excursion Balance Test with real ankle balance taping (black bars) and placebo ankle balance taping (white bars). The y-axis shows the number of positive responses in stability, reassurance, and confidence, compared to those during the control trial

4. The difference between the proportions of each perception

The chi-square analysis showed a significant difference between the proportions of each perception provided by the participants for each of the ABT condition (all $p<$ $0.01)$. 


\section{VV. Discussions}

The results of this study showed that the weight-bearing ankle dorsiflexion ROM did not differ among the 3 conditions. The kinesiology tape used in this study has an elasticity of $80 \%$ of its original length and allows free movement in its range of elasticity (Kaya et al, 2011). Although the performance of rigid adhesive tape was not compared with that of the kinesiology tape in this study, it is worthwhile to note that unlike the limitation of ROM by ankle taping using rigid adhesive tape (Fumich et al, 1981; Bunch et al, 1985), the elasticity of kinesiology tape allows free weight-bearing ankle dorsiflexion ROM.

The reach distances in the 3 selected directions during the SEBT did not show any difference under the 3 different conditions. The weight-bearing ankle dorsiflexion ROM has been shown to contribute to anterior reach distance in the SEBT in healthy subjects (Hoch et al, 2011). However, there was no difference in the anterior reach distance among the different conditions because there was no difference among the weight-bearing ankle dorsiflexion ROM among each of the 3 conditions. In addition, the posteromedial and posterolateral reach distances in the SEBT have been shown to be particularly associated with the status of the hip musculature (Hubbard et al, 2007) and hip and knee flexion ROM (Robinson and Gribble, 2008). However, there was no change in the reach distances in these directions, among the 3 conditions, because the participants of this study did not actually present with problems of hip musculature and limitation of hip and knee ROM. Although ABT did not produce immediate improvement of dynamic balance, the flexibility allowed by ABT did not cause a decrease in the reach distance in the 3 directions during modified SEBT.

The elasticity of the kinesiology tape used in this study may help to support joint structure (Jaraczewska and Long 2006; Lee and Yoo, 2011), and may stimulate the proprioceptive and sensorimotor systems (Murray and
Husk, 2001; Chang et al, 2010). This study showed that the participants' perception of stability, reassurance, and confidence on the modified SEBT test improved with ABT when compared to that with no taping. This may be related to the support, proprioceptive stimulation, and psychological benefit offered by kinesiology taping. However, the role of $\mathrm{ABT}$ in the prevention of ankle injury is merely speculative and its assessment is beyond the scope of this study. Further research is needed to ascertain its effect on prevention of ankle injury.

The limitations of this study were as follows: (1) it was difficult to standardize the results of weight-bearing ankle dorsiflexion ROM and modified SEBT because the participants' ankles were in a pain-free state; (2) the effects of KT for weight-bearing ankle dorsiflexion ROM and modified SEBT were not compared with those of traditional rigid tape; (3) dynamic balance can be assessed using various methods, and in this study, only SEBT was administered.

\section{Conclusion}

This study showed that although real ABT did not immediately improve the reach distances of the 3 selected directions of SEBT in asymptomatic subjects, it improved participants' perception of stability, reassurance, and confidence without decreasing the weight-bearing ankle dorsiflexion ROM. Further studies are needed to investigate the effect of ABT in preventing ankle injury and the clinical effects of $\mathrm{ABT}$ in patients with ankle sprain or instability.

\section{Acknowledgment}

This work was supported by a Dong-Eui University Research Grant NO 2014AA103. 


\section{References}

Bell DR, Guskiewicz KM, Clark MA, et al. Systematic review of the balance error scoring system. Sports Health. 2011;3(3):287-95.

Bennell KL, Talbot RC, Wajswelner H, et al. Intrarater \& inter-rater reliability of a weight-bearing lunge measure of ankle dorsi-flexion. Aust J Physiother. 1998;44(3):175-80.

Bunch RP, Bednarski K, Holland D, et al. Ankle joint support: a comparison of reusable lace-on braces with taping and wrapping. Phys Sportsmed. 1985;13(5):59-62.

Chang HY, Chou KY, Lin JJ, et al. Immediate effect of forearm Kinesio taping on maximal grip strength and force sense in healthy collegiate athletes. Phys Ther Sport. 2010;11(4):122-7.

Cortesi M, Cattaneo D, Jonsdottir J. Effect of kinesio taping on standing balance in subjects with multiple sclerosis: A pilot study. NeuroRehabilitation. 2011;28(4): 365-72.

Coughlan GF, Fullam K, Delahunt E, et al. A Comparison between performance on selected directions of the Star Excursion Balance Test and the Y Balance Test. J Athl Train. 2012;47(4):366-71.

Fumich RM, Ellison AE, Cuerin GI, et al. The measured effect of taping on combined foot and ankle motion before and after exercise. Am J Sports Med. 1981;9(3): 165-70.

García-Muro F, Rodríguez-Fernández AL, Herrero-de-Lucas A. Treatment of myofascial pain in the shoulder with Kinesio Taping. A case report. Man Ther. 2010;15(3): 292-5.

Green T, Refshauge K, Crosbie J, Adams R. A randomized controlled trial of a passive accessory joint mobilization on acute ankle inversion sprains. Phys Ther. 2001; 81(4):984-94.

Gribble PA, Hertel J. Considerations for normalizing measures of the Star Excursion Balance Test. Measure Phys
Ed Exerc Sci. 2003;7(2):89-100.

Gribble PA, Hertel J, Plisky P. Using the Star Excursion Balance Test to assess dynamic postural-control deficits and outcomes in lower extremity injury: a literature and systematic review. J Athl Train. 2012;47(3):339-57.

Hertel J, Miller SJ, Denegar CR. Intratester and intertester reliability during the Star Excursion Balance Tests. J Sport Rehab. 2000;9(2):104-16.

Hoch MC, Staton GS, McKeon PO. Dorsiflexion range of motion significantly influences dynamic balance. J Sci Med Sport. 2011;14(1):90-2.

Huang CY, Hsieh TH, Lu SC, et al. Effect of the kinesio tape to muscle activity and vertical jump performance in healthy inactive people. Biomed Eng OnLine. 2011;10:70.

Hubbard TJ, Kramer LC, Denegar CR, et al. Correlations among multiple measures of functional and mechanical instability in subjects with chronic ankle instability. J Athl Train. 2007;42(3):361-6.

Hwang-Bo G, Lee JH. Effects of kinesio taping in a physical therapist with acute low back pain due to patient handling: a case report. Int J Occup Med and Environ Health. 2011;24(3):320-3.

Janssen KW, Kamper SJ. Ankle taping and bracing for proprioception. Br J Sports Med. 2013;47(8):527-8.

Janssen KW, van Mechelen W, Verhagen EA. Bracing superior to neuromuscular training for the prevention of self-reported recurrent ankle sprains: a three-arm randomised controlled trial. $\mathrm{Br} \mathrm{J}$ Sports Med. 2014;48(16):1235-9.

Jaraczewska, E. Long C. Kinesio ${ }^{\circledR}$ taping in stroke: improving functional use of the upper extremity in hemiplegia. Top Stroke rehabil. 2006;13(3):31-42.

Jones R, Carter J, Moore P, et al. A study to determine the reliability of an ankle dorsiflexion weight-bearing device. Physiotherapy. 2005;91(4):242-9.

Kase K, Wallis J, Kase T. Clinical Therapeutic Applications of the Kinesio ${ }^{\circledR}$ Taping Method(2nd edition), NM: 
Kinesio® Taping Association, Albuquerque, 2003.

Kaya E, Zinnuroglu M, Tugcu I. Kinesio taping compared to physical therapy modalities for the treatment of shoulder impingement syndrome. Clin Rheumatol. 2011;30(2):201-7.

Kemler E, van de Port I, Backx F, et al. A systematic review on the treatment of acute ankle sprain: brace versus other functional treatment types. Sports Med. 2011;41(3):185-97.

Kinzey SJ, Armstrong CW. The reliability of the star excursion test in assessing dynamic balance. J Orthop Sports Phys Ther. 1998;27(5):356-60.

Lee JH, Yoo WG. Application of posterior pelvic tilt taping for the treatment of chronic low back pain with sacroiliac joint dysfunction and increased sacral horizontal angle. Phys Ther Sport. 2012a;13(4): 279-85.

Lee JH, Yoo WG. Effect of scapular elevation taping on scapular depression syndrome: A case report. J Back Musculoskelet Rehabil. 2012b;25(3):187-91.

Lee JH, Yoo WG. The mechanical effect of anterior pelvic tilt taping on slump sitting by seated workers. Ind Health. 2011;49(4):403-9.

Lee JH, Yoo WG. Treatment of chronic Achilles tendon pain by Kinesio taping in an amateur badminton player. Phys Ther sport. 2012c;13(2):115-9.

Lee JH, Yoo WG, Hwang-Bo G. The immediate effect of anterior pelvic tilt taping on pelvic inclination. J Phys Ther Sci. 2011;23(2):201-3.

Liu SH, Nguyen TM. Ankle sprains and other soft tissue injuries. Curr Opin Rheumatol. 1999;11(2):132-7.

Merino R, Fernández E, Iglesias $\mathrm{P}$, et al. The effect of Kinesio taping on calf's injuries prevention in triathletes during competition. Pilot experience. J Hum Sport Exerc. 2011;6(2):305-8.

Metcalfe RC, Schlabach GA, Looney MA, et al. A comparison of moleskin tape, linen tape, and lace-up brace on joint restriction and movement performance. J Athl Train. 1997;32(2):136-40.

Murray H, Husk L. Effect of Kinesio ${ }^{\mathrm{TM}}$ taping on proprioception in the ankle. J Orthop Sports Phys Ther. 2001;31(1): A-37.

Olmsted LC, Carcia CR, Hertel J, et al. Efficacy of the Star Excursion Balance Tests in detecting reach deficits in subjects with chronic ankle instability. J Athl Train. 2002;37(4):501-6.

Plisky PJ, Rauh MJ, Kaminski TW, et al. Star Excursion Balance Test as a predictor of lower extremity injury in high school basketball players. J Orthop Sports Phys Ther. 2006;36(12):911-9.

Robinson R, Gribble P. Kinematic predictors of performance on the Star Excursion Balance Test. J Sport Rehabil. 2008;17(4):347-57.

Sawkins K, Refshauge K, Kilbreath S, et al. The placebo effect of ankle taping in ankle instability. Med Sci Sports Exerc. 2007;39(5):781-7.

Sugimoto K, Takakura Y, Okahashi K, et al. Chondral injuries of the ankle with recurrent lateral instability: an arthroscopic study. J Bone Joint Surg Am. 2009;91(1): 99-106.

Yasukawa A, Patel P, Sisung C. Pilot study: investigating the effects of Kinesio Taping in an acute pediatric rehabilitation setting. Am J Occup Ther. 2006;60(1): 104-10.

Yeung MS, Chan KM, So CH, et al. An epidemiological survey on ankle sprain. Br J Sports Med. 1994;28(2):112-6. 